\title{
Interaction between $17 \alpha$-ethynylestradiol hormone with Langmuir monolayers: The role of charged headgroups
}

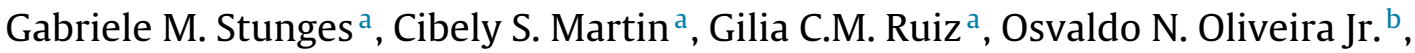 \\ Carlos J.L. Constantino ${ }^{\mathrm{a}, *}$, Priscila Alessio ${ }^{\mathrm{a}, *}$ \\ a São Paulo State University (UNESP), School of Technology and Applied Sciences, Presidente Prudente, SP, 19060-080, Brazil \\ b São Carlos Institute of Physics - University of São Paulo, CP 369, 13560-970 São Carlos, SP, Brazil
}

\section{A R T I C L E I N F O}

Article history:

Received 20 February 2017

Received in revised form 29 June 2017

Accepted 15 July 2017

Available online 17 July 2017

Keywords:

Langmuir monolayer

Phospholipid

Biomembrane model

$17 \alpha$-ethynylestradiol

Pm-irras

\begin{abstract}
A B S T R A C T
The persistence of steroid hormones disposed of in the environment may pose risks to the health of humans and wildlife, which brings the need of understanding their mode of action, believed to occur in cell membranes. In this study, we investigate the molecular-level interactions between the synthetic hormone $17 \alpha$-ethynylestradiol (EE2) and Langmuir monolayers that represent simplified cell membranes. In surface pressure isotherms, EE2 was found to expand the monolayers at low surface pressures of the positively charged dimethyldioctadecylammonium bromide (DODAB), zwitterionic 1,2-dipalmitoyl-sn-glycerol-3-phosphocholine (DPPC), negatively charged 1,2-dipalmitoyl-sn-glycero-3phosphoglycerol (DPPG), and partially anionized stearic acid (StAc). The largest effects were observed for the charged DODAB and DPPG. At the pressure $\left(30 \mathrm{mN} \cdot \mathrm{m}^{-1}\right)$ corresponding to the molecular packing of a cell membrane, EE2 caused the compressibility modulus to decrease, again with the largest changes occurring for DODAB and DPPG. The effects from EE2 on the packing of the lipid molecules at this high pressure depended essentially on the size of the headgroups, with EE2 contributing to the area per lipid for StAc and DODAB, whose headgroups are small. EE2 interacted with the headgroups of all lipids and $\mathrm{StAc}$, also affecting the ordering of the tails for DODAB, DPPG and DPPC, according to in situ polarizationmodulated infrared reflection absorption spectroscopy (PM-IRRAS). Based on the analysis with the two characterization methods, we propose a model for the EE2 positioning and molecular groups involved in the interaction, which should be relevant to unveil the endocrine disrupting action of EE2.
\end{abstract}

(c) 2017 Elsevier B.V. All rights reserved.

\section{Introduction}

The direct disposal of pesticides, pharmaceutical drugs and other chemicals to the environment has been a cause of concern for decades, and this now applies to the indirect disposal of drugs by humans through their urine and feces $[1,2]$. These drugs disposed of may have potential damage to animals and humans, since they are not removed in sewage treatment plants. Particularly relevant are those of continued use, including hormones classified as endocrine-disrupting chemicals [3] that affect endocrine systems of humans and wildlife. Examples of endocrine-disrupting agents include $17 \alpha$-estradiol, E2 (natural hormone), and $17 \alpha$ ethynylestradiol, EE2 (synthetic estrogen) [4-6]. The synthetic EE2, derived from the natural estrogen E2, is used in oral contracep-

\footnotetext{
* Corresponding authors.

E-mail addresses: case@fct.unesp.br (C.J.L. Constantino), priscila@fct.unesp.br (P. Alessio).
}

tives, estrogen replacement therapy, treatment of prostatic cancer, breast cancer, and for postmenopausal women [7]. The amount of estrogen disposed of in the environment is estimated as $4.4 \mathrm{~kg}$ per year for one million inhabitants [4], based on estrogen excretion from men and women, including those pregnant and during the menstrual period $[8-10]$, and from contraceptive pills $[8,10]$.

The risks posed by endocrine disruptors are not known in detail. [11] Most of the literature on synthetic estrogens, particularly EE2, is dedicated to analytical methods for detection and quantification of their active principles [7,12]; studies on possible problems arising from chronic exposure to these compounds are scarce. In fact, the World Health Organization admits the knowledge gap about the risks associated with exposure to low concentrations of drugs in the long run. Effects on the fertility and reproduction of some fish species have been reported even for low concentrations of EE2 (of the order of $\mathrm{ngL}^{-1}$ ) in aquatic systems $[13,14]$. Also unknown are the molecular mechanisms that govern the action of endocrine disruptors. They are believed to have different modes and levels of action in the signaling pathway of human hormones, including 
synthesis, transport and metabolism [15]. In aquatic environments, these disruptors were found to change the structure of biological membranes and organelles [16].

In fact, determining the interaction between steroids (drugs in general) and cell membranes is crucial to understand their therapeutic (or toxic) effects. Since in vivo studies are not feasible at present, researchers have resorted to models mimicking the cell membrane, which include vesicles [17] and Langmuir monolayers at the air/water interface $[18,19]$.

In this study, we use lipid Langmuir monolayers as cell membrane models with the aim of investigating the interaction with the hormone estrogen EE2. Because lipid composition varies widely depending on the type of cell and organism, we opted to perform experiments with distinct types of lipid in order to probe the relevance of charge and headgroup. The lipids are the positively charged dimethyldioctadecylammonium bromide (DODAB), zwitterionic 1,2-dipalmitoyl-sn-glycerol-3phosphocholine (DPPC), and negatively charged 1,2-dipalmitoylsn-glycero-3-phosphoglycerol (DPPG), besides the partially ionized stearic acid (StAc). By limiting the study to such simple lipids, even including StAc which is not a component of cell membrane models, we are able to determine molecular-level interactions involving EE2, especially with in situ polarization-modulated infrared reflection absorption spectroscopy (PM-IRRAS) in addition to surface pressure isotherms.

\section{Materials and methods}

\subsection{Materials}

1,2-Dipalmitoyl-sn-glycerol-3-phosphocholine

(DPPC), dimethyl dioctadecyl ammonium bromide (DODAB), and 1,2Dipalmitoyl-sn-glycero-3-phosphoglycerol (DPPG) with 99\% purity were purchased from Avanti Polar Lipids, Inc. (Alabaster, AL, USA). The synthetic estrogen $17 \alpha$-ethynylestradiol (EE2, purity $\geq 98 \%$ ) and stearic acid (StAc, purity $\geq 99 \%$ ) were purchased from Sigma Chemical Co. (St. Louis, MO, USA). The organic solvents chloroform and methanol were of analytical grade and obtained from Merck ${ }^{\circledR}$ (Germany). Aqueous solutions were obtained with ultrapure Milli- $Q^{\circledR}$ water (resistivity $18.2 \mathrm{M} \Omega . \mathrm{cm}$, surface tension $72 \mathrm{mN} \cdot \mathrm{m}^{-1}$ at $25^{\circ} \mathrm{C}$ ), and $\mathrm{pH}=5.6$.

\subsection{Surface pressure versus mean molecular area $(\pi-A)$ isotherms}

The compounds were dissolved in chloroform, except for DPPG which was dissolved in chloroform/methanol at a 9:1 $(\mathrm{v} / \mathrm{v})$ ratio. The $\pi$-A isotherms were obtained by spreading $0.5 \mathrm{mgmL}^{-1}$ of DPPC, DODAB, DPPG or StAc on either ultrapure water or $4.8 \times 10^{-3}$ EE2 aqueous solution at $(23.0 \pm 0.5)^{\circ} \mathrm{C}$ and compression rate of $5 \mathrm{mmmin}^{-1}$, in a KSV Langmuir trough, model 2000. The concentration of $4.8 \times 10^{-3} \mathrm{mg} / \mathrm{mL}(4.8 \mathrm{ppm})$ corresponds to the solubility of EE2 in water at $20^{\circ} \mathrm{C}$. Furthermore, a concentration below $4.8 \times 10^{-3} \mathrm{mg} / \mathrm{mL}$ does not affect the $\pi$-A isotherms of lipids/EE2. Compression started $10 \mathrm{~min}$ after spreading the compounds to ensure complete solvent evaporation. The $\pi$-A isotherms were obtained in triplicate and the dispersion of the data was below $2 \%$.

\subsection{PM-IRRAS measurements}

Langmuir films on ultrapure water or on $4.8 \times 10^{-3}$ EE2 aqueous solution were compressed up to $\pi=30 \mathrm{mN} \cdot \mathrm{m}^{-1}$ and then the PM-IRRAS spectra were taken with a KSV PMI 550 spectrometer (KSV Instruments Ltd., Helsinki, Finland). This instrument contains a HgCdTe detector (MCT, model PCI-3TE-10.6) with an active area of $1 \times 1 \mathrm{~mm}^{2}$, and the incident infrared beam is modulated by a
ZnSe photoelastic modulator at its resonance frequency of $50 \mathrm{kHz}$. All measurements were performed with the incident light angle of $80^{\circ}$ relative to the normal, with radiation modulated between parallel ( $p$-polarized) or perpendicular ( $s$-polarized) polarizations. The spectra were obtained simultaneously in both polarizations to reduce the water vapor effect. The PM-IRRAS signal $(S)$ is the difference between $s$ and $p$ spectra, i.e. $S=\Delta R / R=(R p-R s) /(R p+R s)$, where $\mathrm{Rp}$ and $\mathrm{Rs}$ are the parallel $(p)$ and perpendicular $(s)$ polarized reflectances, respectively $[20,21]$. The spectral range is $800-4000 \mathrm{~cm}^{-1}$ and the spectral resolution is $8 \mathrm{~cm}^{-1}$.

\section{Results and discussion}

\section{1. $\pi-A$ isotherms}

Fig. 1 shows the $\pi$-A isotherms for Langmuir films of DODAB, DPPC, DPPG, and StAc on ultrapure water and on EE2 at $4.8 \times 10^{-3} \mathrm{mg} \cdot \mathrm{mL}^{-1}$. EE2 interacted with all monolayers, even though it is not sufficiently surface active to form monolayers on its own (see Fig. SI-1). In the condensed phase, EE2 does not contribute to the area per lipid for DPPC and DPPG, and therefore it must be expelled from the air/water interface. It is likely that EE2 molecules can be accommodated in the headgroup region of DPPG and DPPC (underneath), which is sufficiently large. In contrast, the headgroups of DODAB and StAc are small and EE2 affected the packing of these molecules in the condensed phase, by intercalating between DODAB or StAc molecules at the air/water interface and thus contributing to their area per molecule.

In general, interaction with EE2 appears to depend on the monolayer charge. For DPPG, in particular, interactions took place even in the so-called gas phase, at large areas per molecule. Shifts in the surface pressure isotherms were smaller for StAc, which is partially anionized at the interface of an aqueous solution of $\mathrm{pH}$ 5.5-6.0, and for the zwitterionic DPPC. For StAc, the shape of the isotherm is entirely preserved, as if there was no change in film structure; only a shift toward larger areas for the whole isotherm. For DODAB monolayer, the presence of EE2 causes the $\pi$-A isotherm to be shifted even in the condensed phase. We shall return to the discussion of these isotherms while analyzing the PM-IRRAS data, which allows for information on molecular-level interactions to be inferred.

\subsection{Compressional modulus}

The monolayer expansion induced by EE2 affected the compressional modulus $\left(C_{s}^{-1}\right)$ of the monolayers, as shown in Fig. SI-2. $C_{s}^{-1}$ modulus brings additional information about elasticity and compressibility of the monolayers, since its reciprocal is $C_{S}=-\frac{1}{A}\left(\frac{\partial A}{\partial \pi}\right)_{T}$, where $A$ is the area per molecule at a given $\pi . C_{s}{ }^{-1}$ is used for convenience and the properties of Langmuir monolayers compressibility can be determined from the slope of the $\pi$-A isotherms [22], facilitating the comparison with the bulk elastic modulus measured in bilayer systems [23]. In general, $\mathrm{Cs}^{-1}$ depends on the structural state of the monolayer, being higher for condensed monolayers, indicating low interfacial elasticity $[24,25]$. According to the literature $[22,26], C_{s}^{-1}$ for condensed (or solid phase) states ranges from 1000 to $2000 \mathrm{mN} . \mathrm{m}^{-1}$; it varies between 100 and $250 \mathrm{mN} . \mathrm{m}^{-1}$ for liquid condensed (LC) states and ranges from 12.5 to $50 \mathrm{mN} . \mathrm{m}^{-1}$ for liquid expanded (LE) states.

$C_{s}^{-1}$ for DODAB monolayer is consistent with the LE phase, while values typical of LC phase are observed for DPPC and DPPG monolayers. The condensed phase of StAc gives very high $C_{s}^{-1}$, as in a solid phase. EE2 causes all the monolayers to have a reduced $C_{s}^{-1}$; the monolayers become more compressible with incorporation of EE2, especially for the charged DODAB and DPPG. At $30 \mathrm{mN} \cdot \mathrm{m}^{-1}$, which is the pressure believed to correspond to a real cell mem- 

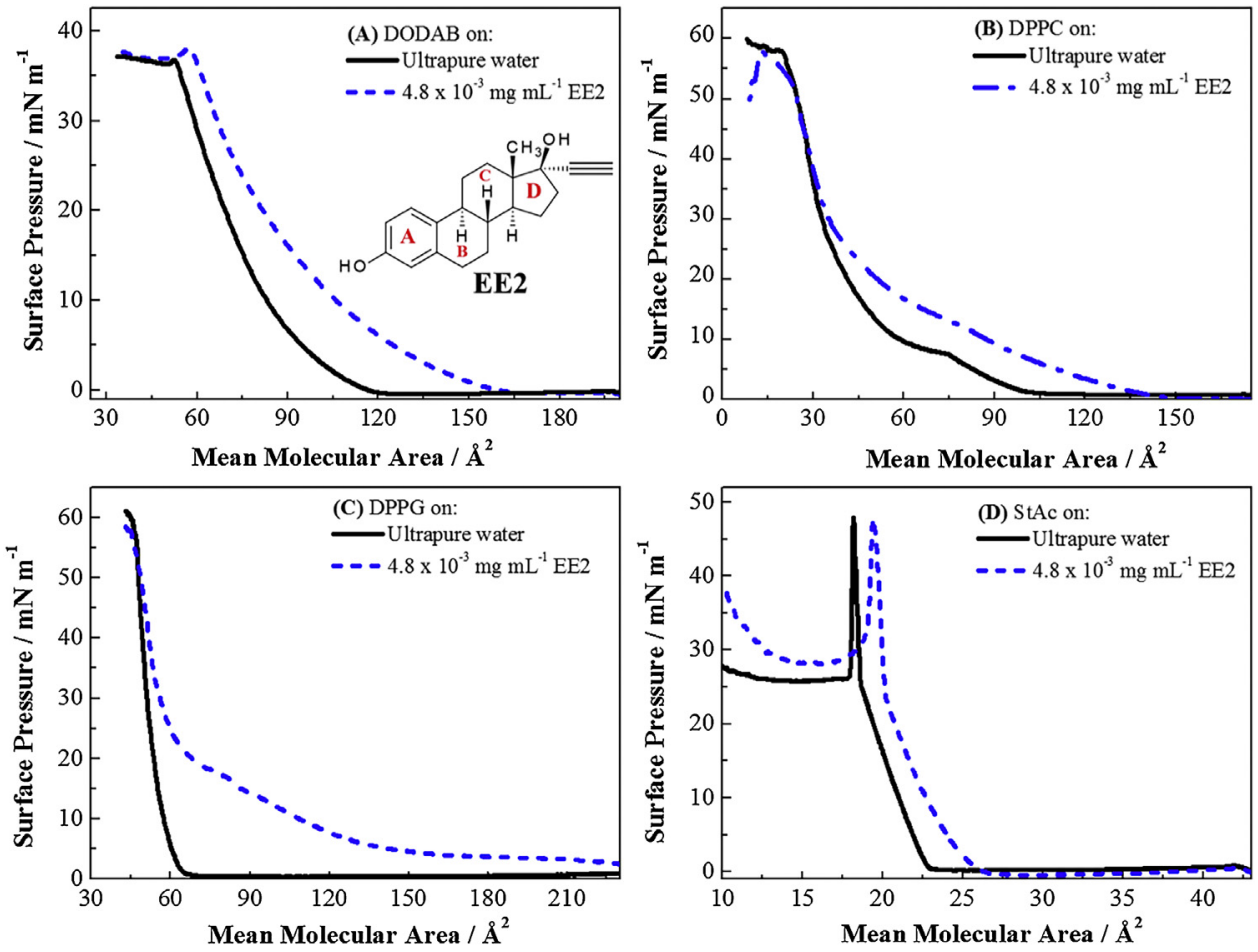

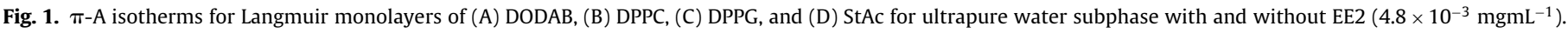
The detail in (A) shows the molecular structure of EE2.

brane $[27,28], C_{S}^{-1}$ decreased by $60 \%$ for DODAB, $57 \%$ for DPPG, $13 \%$ for DPPC, and $12 \%$ for StAc (from Fig. SI-2). These decreases are in line with the area expansion in the isotherms at $30 \mathrm{mN} / \mathrm{m}\left(7 \AA^{2}\right.$ for DODAB, $5.5 \AA^{2}$ for DPPG, $2 \AA^{2}$ for DPPC, and $1.3 \AA^{2}$ for StAc - see Fig. SI-3).

\subsection{PM-IRRAS at $30 \mathrm{mN} \cdot \mathrm{m}^{-1}$ (condensed phase)}

Fig. 2 shows the PM-IRRAS spectra from 2800 to $3000 \mathrm{~cm}^{-1}$, featuring $\mathrm{CH}_{2}$ symmetric and antisymmetric stretchings and $\mathrm{CH}_{3}$ stretching [29-31], for Langmuir films at $30 \mathrm{mN}^{-1} \mathrm{~m}^{-1}$ (condensed phase) of (A) DODAB, (B) DPPC, (C) DPPG, and (D) StAc for ultrapure water and with EE2 at $4.8 \times 10^{-3} \mathrm{mg} \cdot \mathrm{mL}^{-1}$. No effect at all from EE2 was observed for StAc, while the most significant effect occurred for DODAB.

The effects induced by EE2 on the alkyl chains can be analyzed more quantitatively by calculating the relative intensity of the $\mathrm{CH}_{2}$ symmetric stretching in relation to $\mathrm{CH}_{2}$ antisymmetric stretching $\left(v s \mathrm{CH}_{2} / v a s \mathrm{CH}_{2}\right)$, which increases with the disorder of the monolayer chains [31-33]. Fig. SI-4 shows that the largest change occurred for DODAB $\left(\Delta_{\mathrm{RI}}=0.2\right)$, which means that EE2 decreases the order of DODAB alkyl chains. Taking this observation together with the expansion in the surface pressure isotherm of Fig. 1A, we may conclude that EE2 may be embedded within the hydrophobic region of the DODAB monolayer even at high pressures. On the other hand, since the DODAB hydrophilic headgroups were also found to interact with EE2 (see below), it is possible that the chain ordering was affected by such interaction, without EE2 penetration into the hydrophobic chains. The second most affected monolayer was DPPG, followed by DPPC, and no effect was observed for StAc. Indeed, further analysis is required for StAc since its surface pressure isotherm in Fig. 1D was shifted to larger areas. This shift can only be explained by assuming that EE2 should remain at the interface (i.e. in the hydrophilic headgroup region), perhaps even intercalating between StAc molecules whose headgroup is too small to accommodate EE2, but the ordering of the StAc chains would be preserved.

In contrast to the small changes in the PM-IRRAS spectra associated with the alkyl chains, considerable effects of incorporating EE2 were observed in the spectral region between 1000 and $1800 \mathrm{~cm}^{-1}$, whose bands are associated with hydrophilic head groups. Fig. 3 shows that EE2 caused significant changes for all monolayers at $30 \mathrm{mN} \cdot \mathrm{m}^{-1}$. Table 1 (Supplementary information) gives the band assignments [34-36]. For DODAB in Fig. 3A, a considerable change took place in the so-called water deformation band, which will be discussed separately later on. Another strong effect was probably caused by ion-dipole attraction between the cationic DODAB hydrophilic head (quaternary $\mathrm{N}^{+}$) and EE2 $\mathrm{OH}$ groups, i.e. A-ring or D-ring (see EE2 detail in Fig. 1), which affected the antisymmetric deformation of $\mathrm{CH}_{3}\left(\mathrm{~N}^{+}\right)$at ca. $1490 \mathrm{~cm}^{-1}$ [37]. This hypothesis is based on the theoretical calculations by Scheidt et al. [38] who reported that the hydroxyl of A-ring is more hydrophilic than in a D-ring. Nakata et al. [39] also reported that DMPC membrane interacts with estradiol, cholesterol, and estrone through the $\mathrm{OH}$ group from A-ring; however, no interaction was observed with testosterone owing to the lack of a $\mathrm{OH}$ group at the A-ring. The attractive DODAB-EE2 interaction must be relatively strong, because the $\pi$-A isotherm in Fig. 1A was still shifted even in the condensed phase, indicating that EE2 molecules are kept between DODAB molecules (intercalating) at the air/water interface, despite the lateral pressure. The interaction between cationic lipids and phenolic groups was reported by Paiva et al. [40], who described the production of organophilic ceramics with added cationic lipids used in water treatment. These lipids act as surfactants and increase adsorption of phenolic-containing molecules, reinforcing the hypothesis of iondipole attractive interaction between DODAB and EE2.

The $\mathrm{P}=\mathrm{O}$ stretching band in DPPC and DPPG and the $\mathrm{C}=\mathrm{O}$ stretching band for StAc in Fig. 3B through 3D were shifted to lower wavenumbers (see Table 1 in Supplementary information). These shifts are assigned to H-bonding between EE2 and the hydrophilic 

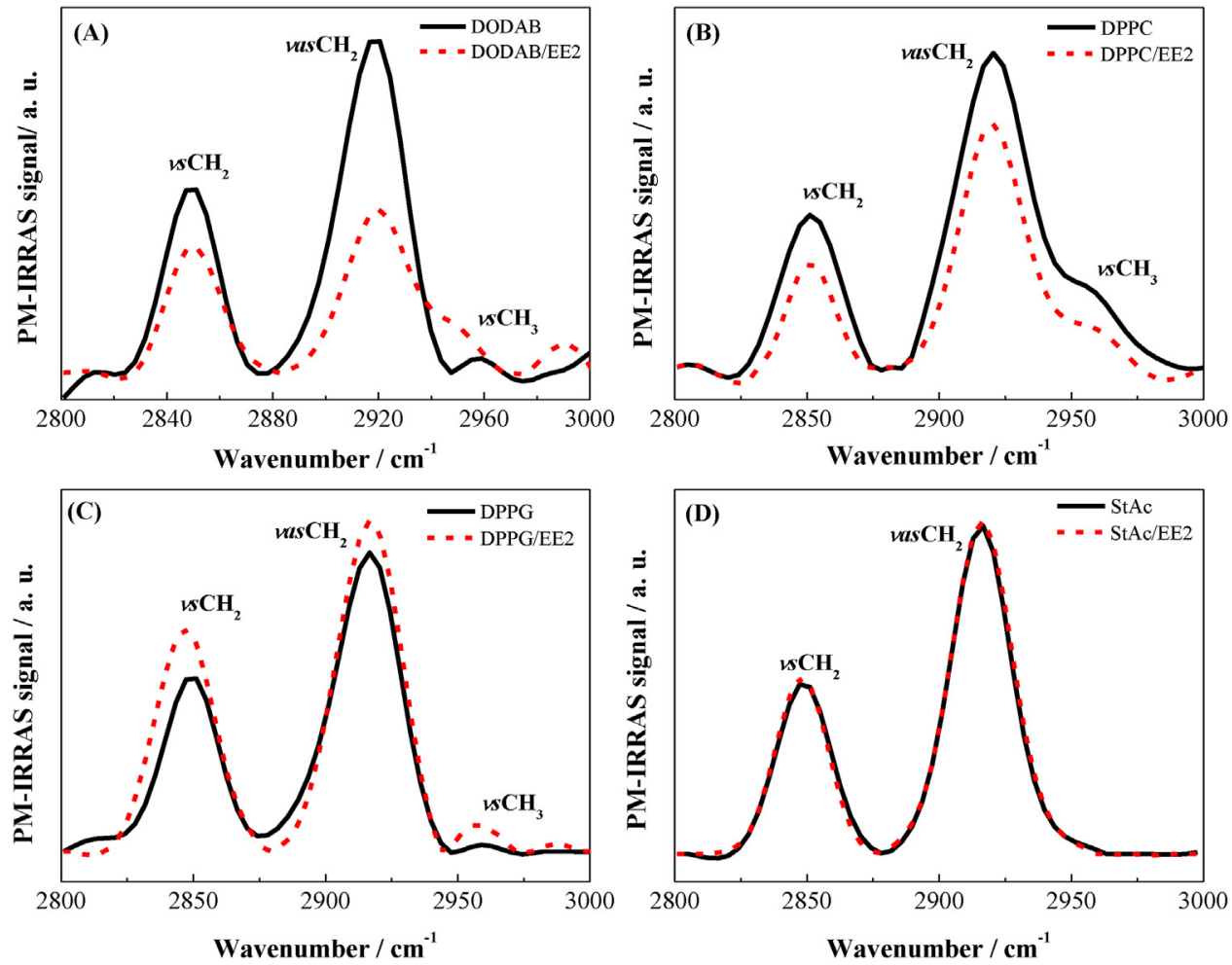

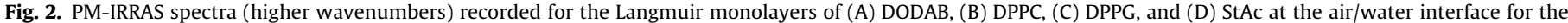
ultrapure water subphase with and without EE2 $\left(4.8 \times 10^{-3} \mathrm{mg} \cdot \mathrm{mL}^{-1}\right)$ at $30 \mathrm{mN} \cdot \mathrm{m}^{-1}$ (condensed phase). $v_{\mathrm{s}}$ : symmetric stretching; $v_{\text {as }}$ : antisymmetric stretching.
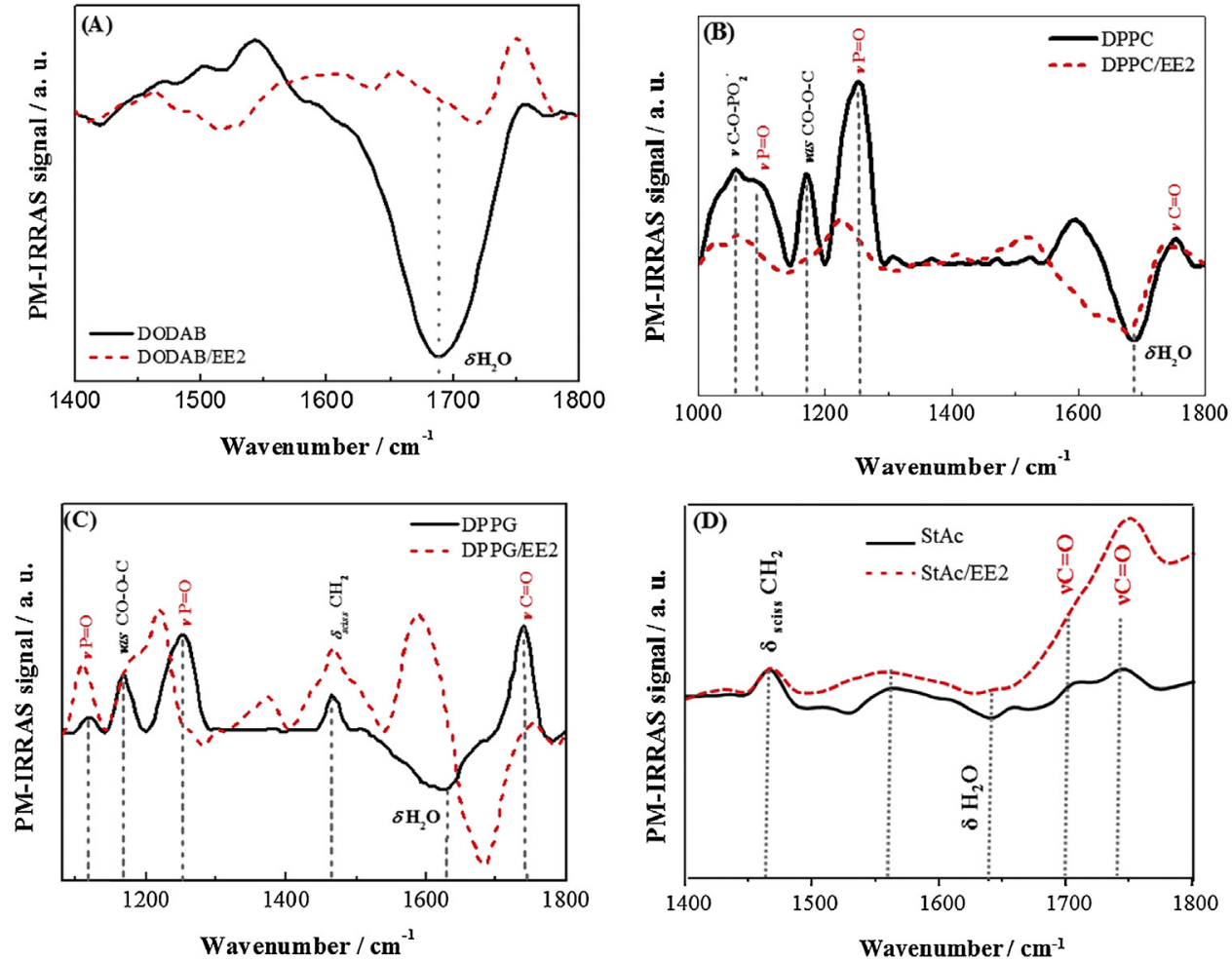

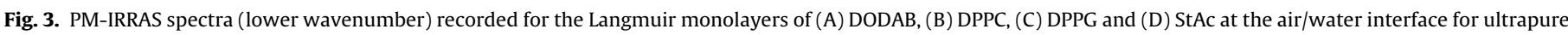
water subphase with and without EE2 $\left(4.8 \times 10^{-3} \mathrm{mg} \cdot \mathrm{mL}^{-1}\right)$ at $30 \mathrm{mN} \cdot \mathrm{m}^{-1}$. $v$ : stretching; $\delta$ : bending.

region of monolayers $(\mathrm{P}=\mathrm{O}$ and $\mathrm{C}=\mathrm{O}$ groups $)$ [34-36], consistent with the literature $[39,41]$.

In the case of the zwitterionic DPPC, ion-dipole interactions must take place. The $\mathrm{OH}$ group of EE2 can be attracted by the cationic group of the DPPC hydrophilic head (quaternary $\mathrm{N}^{+}$), in addition to being repelled by the anionic group of DPPC $\left(\mathrm{PO}_{4}^{-}\right)$, which counteracts the ion-dipole DPPC-EE2 attractive interaction. DPPC and EE2 can also interact through H-bonding. Dimitrov and 
A) DODAB

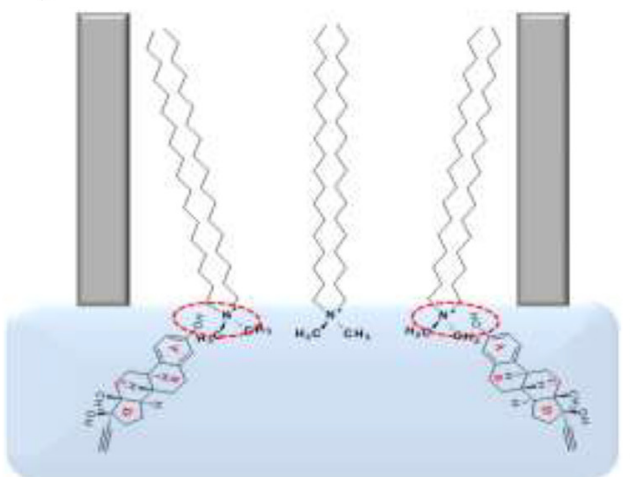

C) DPPG

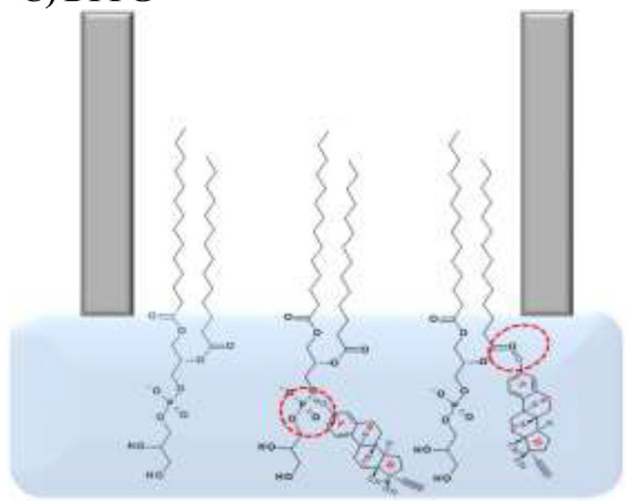

B) DPPC

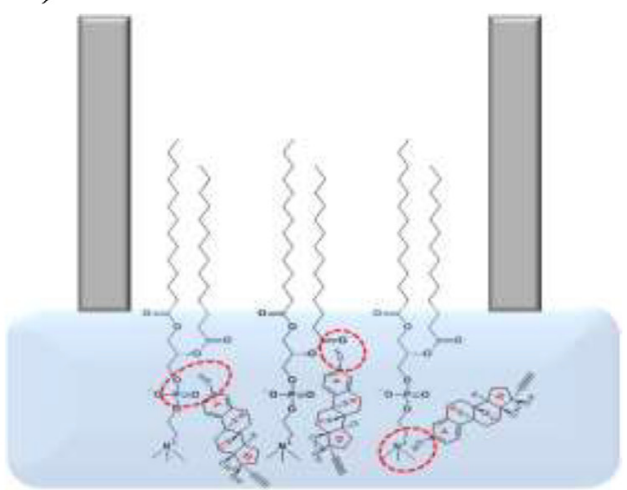

D) StAc

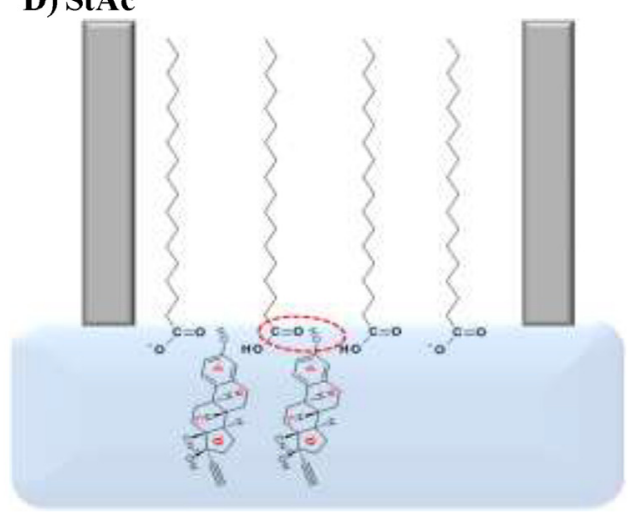

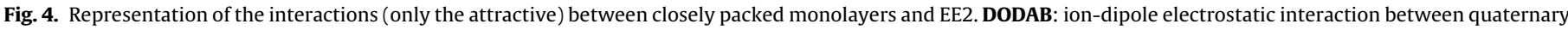

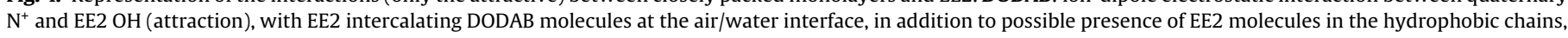

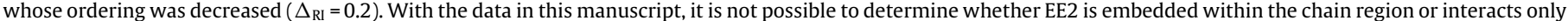

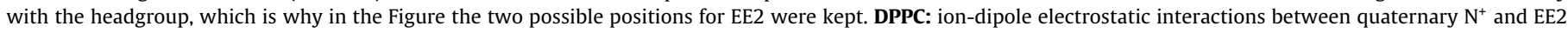

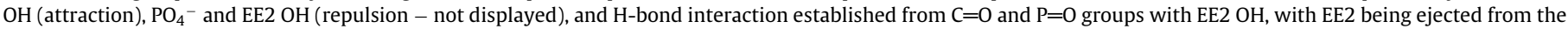

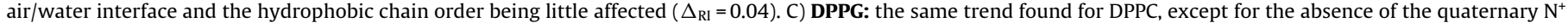

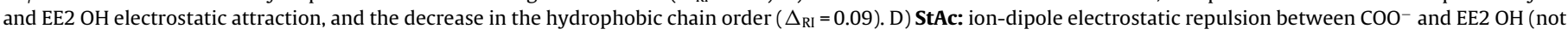

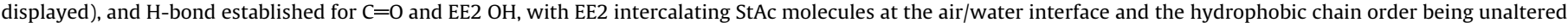
$\left(\Delta_{\mathrm{RI}}=0\right)$. The EE2 OH refers to the hydroxyl from A-ring.

Lalchev [41] observed that steroids containing hydroxyl groups in the A-ring display more significant attractive interactions with DPPC molecules than steroids with hydroxyls at the D-ring. The authors concluded that a shift to larger areas in $\pi$-A isotherms by co-spreading $17 \alpha$-estradiol (E2) and DPPC can be assigned to $\mathrm{H}-$ bonds between the hydroxyl of the E2 A-ring and the $\mathrm{C}=\mathrm{O}$ group of DPPC, as observed for cholesterol as well. These studies are also consistent with those by Nakata et al. [39] and Scheidt et al. [38], mentioned above in the discussion for DODAB. Another possible mechanism of attractive interaction is between the $\mathrm{P}=\mathrm{O}$ group of DPPC and the $\mathrm{OH}$ group of EE2 A-ring, since $\mathrm{P}=\mathrm{O}$ is sensitive to H-bond formation [42]. These results support the hypothesis of DPPC-EE2 interactions through the hydrophilic groups of the DPPC head with the $\mathrm{OH}$ groups of the EE2 A-ring, leading to ion-dipole (quaternary $\mathrm{N}^{+} / \mathrm{OH}$ : attraction; $\mathrm{PO}_{4}^{-} / \mathrm{OH}$ : repulsion) and $\mathrm{H}$-bond ( $\mathrm{C}=\mathrm{O} / \mathrm{HO}$ and $\mathrm{P}=\mathrm{O} / \mathrm{HO}$ : attraction $)$ as driving mechanisms.

The molecular-level interactions involving EE2 in DPPG monolayers may be similar to those for DPPC. One may expect $\mathrm{H}-$ bonds between $\mathrm{C}=\mathrm{O}$ (DPPG) and $\mathrm{OH}(\mathrm{EE} 2), \mathrm{P}=\mathrm{O}$ (DPPG) and $\mathrm{OH}$ (EE2), and ion-dipole repulsion between $\mathrm{PO}_{4}{ }^{-}$(DPPG) and $\mathrm{OH}$ (EE2).

Since StAc has only $\mathrm{C}=\mathrm{O}$ and $\mathrm{OH}$ groups in the hydrophilic head, a more detailed analysis of the PM-IRRAS spectrum can be done. At $\mathrm{pH} \sim 5.6$ of ultrapure water, the carboxylic groups of a StAc monolayer are partially ionized [43], thus presenting $\mathrm{COOH}$ and $\mathrm{COO}^{-}$ groups. Therefore, EE2 could establish $\mathrm{H}$-bond via its $\mathrm{OH}$ group (A-ring) with $\mathrm{C}=\mathrm{O}$ of StAc and possibly an ion-dipole repulsion with $\mathrm{COO}^{-}$group. The increase in $\mathrm{C}=\mathrm{O}$ stretching at $1748 \mathrm{~cm}^{-1}$ induced by EE2 may be explained by changes in conformation of StAc molecules as follows. StAc may adopt three types of conformation at the air/water interface [44]: i) type I: $\mathrm{C}=0$ group parallel to water surface, which shows an intense band at $1736 \mathrm{~cm}^{-1}$; ii) type II: both $\mathrm{C}=\mathrm{O}$ and $\mathrm{C}-\mathrm{OH}$ groups equally facing the water, with a band at $1724 \mathrm{~cm}^{-1}$ and no significant changes are expected with rotation of carboxylic group; iii) type III: $\mathrm{C}=0$ groups are involved in the $\mathrm{H}$-bond network between StAc molecules, being more hydrated and stable, whose band is observed at ca. $1705 \mathrm{~cm}^{-1}$. The spectrum for StAc here shows conformations of type I and III simultaneously, i.e. the $\mathrm{StAc}$ molecules show the $\mathrm{C}=\mathrm{O}$ groups oriented parallel to the air/water interface, forming $\mathrm{H}$-bonds. In the presence of EE2, an increase of type I band at $1747 \mathrm{~cm}^{-1}$ and a decrease of type III band at $1707 \mathrm{~cm}^{-1}$ were observed. These indicate interaction of EE2 preferentially with $\mathrm{C}=\mathrm{O}$ at type I conformation, decreasing $\mathrm{H}$-bonds between StAc molecules.

The negative dips in the PM-IRRAS spectra of Fig. 3 are ascribed to angular deformation (bending) of water molecules $\left(\mathrm{\delta OH}_{2}\right)$ at the air/water interface. This allows one to infer changes in the orientation of water molecules from the difference in reflectivity of the air/water interface induced by the monolayer [33,45,46]. According to theoretical studies by Blaudez et al. [46], the appearance and intensity of the negative dip depend on the nature of the monolayer and interaction with water molecules. In Fig. 3, EE2 was found to affect the spectra of all lipids (DODAB, DPPC, DPPG and 
StAc). The decrease in intensity of the $\delta \mathrm{OH}_{2}$ band induced by EE2 occurred in the following order: DPPG ( 300\%)> DODAB ( 150\%)> StAc $(\sim 50 \%)>$ DPPC $(\sim 10 \%)$, thus pointing to the importance of the monolayer charge.

The results described and discussed in this section were all obtained at $30 \mathrm{mN} . \mathrm{m}^{-1}$, i.e. for monolayers in the condensed phase. In the Supporting Information (Fig. SI-5) we present data for PMIRRAS spectra obtained for monolayers in the liquid-expanded phase $\left(10 \mathrm{mN} \cdot \mathrm{m}^{-1}\right)$, where band shifts were observed in $\mathrm{CH}_{2}$ and $\mathrm{CH}_{3}$ stretchings for all lipids (DODAB, DPPC, DPPG and StAc) with EE2 in the subphase. These shifts indicate that EE2 interacts with both hydrophilic and hydrophobic regions of the monolayers in the liquid-expanded phase, as one should expect since the lipid molecules are less ordered at this lower surface pressure.

\subsection{Proposed model for molecular-level interactions}

The molecular-level interactions between EE2 and the lipids DODAB, DPPC, DPPG and StAc in Langmuir monolayers discussed in the previous sections can be summarized in a model proposed in Fig. 4. These possible interactions apply to closely packed monolayers at $30 \mathrm{mN} \cdot \mathrm{m}^{-1}$ with EE2 dissolved in the subphase.

\section{Conclusion}

The action as endocrine disruptor of the hormone EE2 hints that it should interact with cell membranes, and this was confirmed here with lipid Langmuir monolayers that may mimic membranes. Indeed, even though EE2 is not surface active, it readily adsorbed on Langmuir monolayers of different types of lipid, causing effects that depended mainly on the monolayer charge. At low surface pressures, EE2 induced expansion in the isotherms of all lipids tested, i.e. DODAB, DPPC, DPPG and StAc. Interaction took place with the hydrophilic headgroup for all lipids and StAc, and with hydrophobic tails for some of them, as indicated in the PM-IRRAS spectra. For condensed monolayers, at pressures believed to correspond to the packing of a real cell membrane, the effects from EE2 were also dependent on the charge of the headgroup. For instance, EE2 decreased the compressional modulus of the monolayers with the largest changes occurring for the charged DODAB and DPPG. Such a dependence on the headgroup charge also applied to the change induced by EE2 in the water deformation band in the PM-IRRAS spectra. With regard to effects on the packing of molecules in the condensed phase, the size of the headgroup was the most dominant factor. For DPPG and DPPC, whose headgroups are large, EE2 did not contribute to the area per lipid in the condensed phase, as it could be accommodated in the headgroup region. In contrast, for StAc and DODAB, whose headgroups are smaller, EE2 did cause an increase in area per molecule.

The molecular-level information inferred from the analysis of the PM-IRRAS spectra allowed us to propose a model for the probable positioning of EE2 and the molecular groups involved in the interaction with the monolayers. For instance, electrostatic iondipole interactions between DODAB (quaternary $\left.\mathrm{N}^{+}\right)$and EE2 $(\mathrm{OH}$ from A-ring mainly) were found to affect monolayer behavior at distinct regimes of surface pressures. H-bonding was also shown to be relevant for DPPC, DPPG, and StAc. In summary, we found that EE2 can interact with monolayers made with positively and negatively charged lipids, in addition to non-charged, zwitterionic lipids. Therefore, interaction of EE2 with the lipids of the cell membrane may be one of the possible steps related to its action as endocrine disruptor.

\section{Acknowledgments}

FAPESP, CNPq and CAPES for the financial support, and Dr. Felippe José Pavinatto for the assistance with PM-IRRAS measurements.

\section{Appendix A. Supplementary data}

Supplementary data associated with this article can be found, in the online version, at http://dx.doi.org/10.1016/j.colsurfb.2017.07. 034.

\section{References}

[1] T. Deblonde, C. Cossu-Leguille, P. Hartemann, Emerging pollutants in wastewater: a review of the literature, Int. J. Hyg. Environ. Health 214 (2011) 442-448.

[2] H. Geissen, E. Mol, G. Klumpp, M. Nadal, M. van der Ploeg, et al., Emerging pollutants in the environment: a challenge for water resource management, Int. Soil Water Conserv. Res. 3 (2015) 57-65.

[3] K.A. Welshons, B.M. Thayer, J.A. Judy, E.M. Curran, F.S. vom Saal, Large effects from small exposures. I. Mechanisms for endocrine-disrupting chemicals with estrogenic activity, Environ. Health Perspect 111 (2003) 994-1006.

[4] L. Barreiros, J.F. Queiroz, L.M. Magalhães, A.M.T. Silva, M.A. Segundo, Analysis of 17 -ã-estradiol and 17- $\beta$-ethinylestradiol in biological and environmental matrices? A review, Microchem. J. 126 (2015) 243-262.

[5] F.A. Caliman, M. Gavrilescu, Pharmaceuticals personal care products and endocrine disrupting agents in the environment - a review, CLEAN - Soil, Air Water 37 (2009) 277-303.

[6] E.J. Rosenfeldt, K.G. Linden, Degradation of Endocrine Disrupting Chemicals Bisphenol A Ethinyl Estradiol, and Estradiol during UV Photolysis and Advanced Oxidation Processes, Environ. Sci. Technol. 38 (2004) 5476-5483.

[7] A.Z. Aris, A.S. Shamsuddin, S.M. Praveena, Occurrence of $17 \alpha$-ethynylestradiol (EE2) in the environment and effect on exposed biota: a review, Environ. Int. 69 (2014) 104-109.

[8] N. Xu, Y.F. Xu, S. Xu, J. Li, H.C. Tao, Removal of estrogens in municipal wastewater treatment plants: a Chinese perspective, Environ. Pollut. (2012) 215-224.

[9] S. Combalbert, G. Hernandez-Raquet, Occurrence fate, and biodegradation of estrogens in sewage and manure, Appl. Microbiol. Biotechnol. 86 (2010) 1671-1692

[10] A.C. Johnson, R.J. Williams, A model to estimate influent and effluent concentrations of estradiol estrone, and ethinylestradiol at sewage treatment works, Environ. Sci. Technol. 38 (2004) 3649-3658.

[11] Y. Lee, U. von Gunten, Transformation of $17 \alpha$-Ethinylestradiol during water chlorination: effects of bromide on kinetics, products, and transformation pathways, Environ. Sci. Technol. 43 (2009) 480-487.

[12] F. Yang, W. Huang, W. Xie, C. Lu, W. Liu, Targeted analytical toxicology: simultaneous determination of $17 \alpha$-ethynylestradiol and the estrogen-induced vitellogenin biomarker, Environ. Int. 74 (2015) 119-124.

[13] C.P. Silva, M. Otero, V. Esteves, Processes for the elimination of estrogenic steroid hormones from water: a review, Environ. Pollut. 165 (2012) 38-58.

[14] L.J. Mills, C. Chichester, Review of evidence: are endocrine-disrupting chemicals in the aquatic environment impacting fish populations? Sci. Total Environ. 343 (2005) 1-34

[15] P.F. Siegenthaler, P. Bain, F. Riva, K. Fent, Effects of antiandrogenic progestins, chlormadinone and cyproterone acetate, and the estrogen $17 \alpha$-ethinylestradiol (EE2), and their mixtures: transactivation with human and rainbowfish hormone receptors and transcriptional effects in zebrafish (Danio rerio) eleuthero-embryos, Aquat. Toxicol. 182 (2017) 142-162.

[16] M.S. Pollock, M.G. Dubé, R. Schryer, Investigating the link between pulp mill effluent and endocrine disruption: attempts to explain the presence of intersex fish in the Wabigoon River Ontario, Canada, Environ. Toxicol. Chem. 29 (2010) 952-965.

[17] N.B. Leite, A. Aufderhorst-Roberts, M.S. Palma, S.D. Connell, J.R. Neto, P.A. Beales, PE and PS Lipids Synergistically Enhance Membrane Poration by a Peptide with Anticancer Properties, Biophys. J. 109 (2015) 936-947.

[18] A. Casadó, M.C. Giuffrida, M.L. Sagristá, F. Castelli, M. Pujol, M.A. Alsina, et al. Langmuir monolayers and Differential Scanning Calorimetry for the study of the interactions between camptothecin drugs and biomembrane models, Biochim. Biophys. Acta. 1858 (2016) 422-433.

[19] W.M. Pazin, D. da S. Olivier, N. Vilanova, A.P. Ramos, I.K. Voets, A.E.E. Soares, et al., Interaction of Artepillin C with model membranes, Eur. Biophys. J. 46 (4) (2017) 383-393, http://dx.doi.org/10.1007/s00249-016-1183-5.

[20] D. Blaudez, T. Buffeteau, J.C. Cornut, B. Desbat, N. Escafre, M. Pezolet, et al, Polarization-Modulated FT-IR spectroscopy of a spread monolayer at the Air/Water interface, Appl. Spectrosc. 47 (1993) 869-874.

[21] H. Nakahara, S. Lee, O. Shibata, Specific interaction restrains structural transitions of an amphiphilic peptide in pulmonary surfactant model systems: an in situ PM-IRRAS investigation, Biochim. Biophys. Acta. 1798 (2010) 1263-1271. 
[22] D. Vollhardt, V.B. Fainerman, Progress in characterization of Langmuir monolayers by consideration of compressibility, Adv. Colloid Interface Sci. 127 (2006) 83-97.

[23] S. Ali, J.M. Smaby, M.M. Momsen, H.L. Brockman, R.E. Brown, Acyl chain-length asymmetry alters the interfacial elastic interactions of phosphatidylcholines, Biophys. J. 74 (1998) 338-348.

[24] K. Gong, S.S. Feng, M.L. Go, P.H. Soew, Effects of pH on the stability and compressibility of DPPC/cholesterol monolayers at the air-water interface, Colloids Surf. A Physicochem. Eng. Asp. 207 (2002) 113-125.

[25] A.A. Torrano, S. Â. Pereira, O.N. Oliveira Jr., A. Barros-Timmons, Probing the interaction of oppositely charged gold nanoparticles with DPPG and DPPC Langmuir monolayers as cell membrane models, Colloids Surf. B. Biointerfaces 108 (2013) 120-126.

[26] S. Ortiz-Collazos, Y.M.H. Gonçalves, B.A.C. Horta, P.H.S. Picciani, S.R.W. Louro, O.N. Oliveira Jr., et al., Langmuir films and mechanical properties of polyethyleneglycol fatty acid esters at the air-water interface, Colloids Surf. A Physicochem. Eng. Asp. 498 (2016) 50-57.

[27] D. Marsh, Lateral pressure in membranes, Biochim. Biophys. Acta - Rev. Biomembr. 1286 (1996) 183-223.

[28] C. Stefaniu, A. Ries, O. Gutowski, U. Ruett, P.H. Seeberger, D.B. Werz, et al., Impact of structural differences in galactocerebrosides on the behavior of 2D monolayers, Langmuir 32 (2016) 2436-2444.

[29] I. Zawisza, A. Lachenwitzer, V. Zamlynny, S.L. Horswell, J.D. Goddard, J. Lipkowski, Electrochemical and photon polarization modulation infrared reflection absorption spectroscopy study of the electric field driven transformations of a phospholipid bilayer supported at a gold electrode surface, Biophys. J. 85 (2003) 4055-4075.

[30] I. Estrela-Lopis, G. Brezesinski, H. Möhwald, Dipalmitoyl-phosphatidylcholine/phospholipase d interactions investigated with polarization-Modulated infrared reflection absorption spectroscopy, Biophys. J. 80 (2001) 749-754.

31] P.H.B. Aoki, L.F.C. Morato, F. Pavinatto, T.M. Nobre C.J.L Constantino, O.N. Oliveira Jr., Molecular-level modifications induced by photo-Oxidation of lipid monolayers interacting with erythrosin, Langmuir 32 (2016) 3766-3773.

[32] I.W. Levin, T.E. Thompson, Y. Barenholz, C. Huang, Two types of hydrocarbon chain interdigitation in sphingomyelin bilayers, Biochemistry 24 (1985) 6282-6286

[33] T.E. Goto, L. Caseli, The interaction of mefloquine hydrochloride with cell membrane models at the air-water interface is modulated by the monolayer lipid composition, J.Colloid Interface Sci. 431 (2014) 24-30.

[34] J.L.R. Arrondo, F.M. Goñi, J. Macarulla, Infrared spectroscopy of phosphatidylcholines in aqueous suspension a study of the phosphate group vibrations, Biochim. Biophys. Acta - Lipids Lipid Metab. 794 (1984) 165-168.
[35] M. Pinheiro, M. Arêde, J.J. Giner-Casares, C. Nunes, J.M. Caio, C. Moiteiro, et al., Effects of a novel antimycobacterial compound on the biophysical properties of a pulmonary surfactant model membrane, Int. J. Pharm. 450 (2013) 268-277.

[36] W. Hübner, A. Blume, Interactions at the lipid-water interface, Chem. Phys. Lipids 96 (1998) 99-123.

[37] F.-G. Wu, Z.-W. Yu, G. Ji, Formation and transformation of the subgel phase in dioctadecyldimethylammonium bromide aqueous dispersions, Langmuir 27 (2011) 2349-2356

[38] H.A. Scheidt, R.M. Badeau, D. Huster, Investigating the membrane orientation and transversal distribution of $17 \beta$-estradiol in lipid membranes by solid-state NMR, Chem. Phys. Lipids. 163 (2010) 356-361.

[39] S. Nakata, A. Ikeguchi, T. Shiota, R. Komori, N. Kumazawa, M. Tsutsumi, et al., Interactions between sex hormones and a

1,2-Di-O-myristoyl-sn-glycero-3-phosphocholine molecular layer: characteristics of the liposome, surface area versus surface pressure of the monolayer, and microscopic observation, Bull. Chem. Soc. Jpn. 84 (2011) 283-289.

[40] L.B. De Paiva, A.R. Morales, F.R.V. Díaz, Argilas organofílicas: características metodologias de preparação, compostos de intercalação e técnicas de caracterização, Cerâmica 54 (2008) 213-226.

[41] O.A. Dimitrov, Z.I. Lalchev, Interaction of sex hormones and cholesterol with monolayers of dipalmitoylphosphatidylcholine in different phase state, J. Steroid Biochem. Mol. Biol. 66 (1998) 55-61.

[42] R. Mendelsohn, G. Mao, C.R. Flach, Infrared reflection-absorption spectroscopy: principles and applications to lipid-protein interaction in Langmuir films, Biochim. Biophys. Acta. 1798 (2010) 788-800.

[43] O.N. Oliveira Jr., D.M. Taylor, H. Morgan, Modelling the surface potential-area dependence of a stearic acid monolayer, Thin Solid Films 210-211 (1992) $76-78$.

[44] M. Muro, Y. Itoh, T. Hasegawa, A conformation and orientation model of the carboxylic group of fatty acids dependent on chain length in a langmuir monolayer film studied by polarization-modulation infrared reflection absorption spectroscopy, J. Phys. Chem. B. 114 (2010) 11496-11501.

[45] J. Saccani, S. Castano, F. Beaurain, M. Laguerre, B. Desbat, Stabilization of phospholipid multilayers at the air-water interface by compression beyond the collapse: a BAM, PM-IRRAS, and molecular dynamics study, Langmuir 20 (2004) 9190-9197.

[46] D. Blaudez, J.-M. Turlet, J. Dufourcq, D. Bard, T. Buffeteau, B. Desbat, Investigations at the air/water interface using polarization modulation IR spectroscopy, J. Chem. Soc. Faraday Trans. 92 (1996) 525-530. 